Original Research Paper

\title{
Program Pengembangan Produk Kewirausahaan yang Berbahan Dasar Pisang (Sate Pisang Varian Rasa) di Desa Tangga Kecamatan Monta Kab. Bima NTB
}

\author{
Putri Rezeki Amelia ${ }^{1}$, Ahmad Raksun* \\ ${ }^{\text {I} P r o g r a m ~ S t u d i ~ P e n d i d i k a n ~ B a h a s a ~ I n g g r i s, ~ F a k u l t a s ~ K e g u r u a n ~ d a n ~ I l m u ~ P e n d i d i k a n, ~ U n i v e r s i t a s ~ M a t a r a m, ~ M a t a r a m, ~}$ \\ Indonesia \\ ${ }^{2}$ Program Studi Pendidikan Biologi, , Fakultas Keguruan dan Ilmu Pendidikan, Universitas Mataram, Mataram, Indonesia
}

DOI: https://doi.org/10.29303/jpmpi.v3i2.571

Sitasi:. Suripto., \& Aksari, S. Y. (2020). Program Pengembangan Produk Kewirausahaan yang Berbahan Dasar Pisang (Sate Pisang Varian Rasa) di Desa Tangga Kecamatan Monta Kab. Bima NTB. Jurnal Pengabdian Magister Pendidikan IPA, 3(2)

\section{Article history}

Received: 25 Oktober

Revised: 15 Nopember

Accepted: 30 Desember

*Corresponding Author:

Ahmad Raksun, Program Studi Pendidikan Biologi, Fakultas

Keguruan dan Ilmu Pendidikan, Universitas Mataram, Mataram, Indonesia

Email:

ahmadunram@unram.ac.id

\begin{abstract}
Desa Tangga termasuk salah satu Desa yang terletak di Kecamatan Monta Kabupaten Bima Nusa Tenggara Barat. Desa tangga merupakan pusat Kecamatan Monta dimana bangunan-bangunan umum kecamatan Monta berada di Desa Tangga seperti, Rumah Sakit, Bank, Kantor Camat, KUA, dll. Desa Tangga Kecamatan Monta memiliki jumlah penduduk dengan KK 980 orang yang terdir terdiri dari laki-laki: 1897 jiwa, perempuan 1997 jiwa, sebagian besar dari jumlah masyarakat berprofesi sebagai petani, peternak, PNS dan buruh tani, sebagianya lagi tidak bekerja. Desa Tangga merupakan salah satu Desa penghasil pisang terbesar di Kecamatan monta, Hal ini yang perlu mendapat sorotan dan perhatian kami dari Universitas Mataram untuk segera memberi solusi yaitu solusi di bidang sosial dan ekonomi kemasyarakatan. Solusi dibidang ekonomi antara lain warga masyarakat di desa Tangga mendapat hasil yang lebih baik dari pengolahan pisang sebelumnya yaitu dengan cara menggoreng dan merebus menjadi berbagai macam cemilan enak dan sehat seperti sate pisang, pisang keju, kripik pisang, brongko, dan aneka cemilan lainnya yang harganya lebih mahal. Langkah yang diambil adalah memberikan mereka pengetahuan dan mengajarkan serta melatih mereka untuk mengolah pisang tersebut untuk di jadikan beberapa menu cemilan yang enak, sehat dan berdaya jual tinggi.
\end{abstract}

Keywords: Pisang; Aneka Cemilan; Sate Pisang

\section{Pendahuluan}

Kreativitas pengetahuan dan akses terhadap informasi merupakan jalan yang mendukung pertumbuhan Ekonomi dalam meningkatkan pembangunan Ekonomi secara menyeluruh. Unsurunsur penting yang mendukung pertumbuhan ekonomi adalah usaha dengan tingkat kreatifitas yang tinggi. usaha dengan kreativitas tinggi, dapat menjadi komponen penting dalam pertumbuhan Ekomoni serta mengarah pada meluasnya lapangan pekerjaan baik dalam kelompok masyarakat kecil maupun dalam kelompok masyarakat besar.
Usaha yang unik dan kreatif akan menjadi trend dalam beberapa tahun mendatang. Selaras dengan itu, kita dapat melihat terjadinya stagnasi pertumbuhan Ekonomi dan gradasi lingkungan

yang semakin memprihatinkan, hal ini mendorong seluruh dunia untuk lebih mengedepankan kreativitas dalam membagun dan menciptakan produk yang cukup unik dalam membangun, menunjang, serta memaksimalkan nilai tambah dari barang dan jasa sebagai bentuk antisipasi terhadap keberlanjutan kehidupan dan peradaban manusia.

Program pengembangan suatu usaha di kalangan masyarakat desa akan sangat berperan 
penting dalam sektor pemberian edukasi kepada masyarakat setempat yang masih kurang paham dengan berbagai macam bentuk usaha yang memiliki keunikan dan daya jual tinggi. Untuk itu, dengan adanya terobosan dari mahasiswa, maka diharapkan masyarakat termotivasi untuk mengembangkan wirausaha yang telah dilakoni sehingga tingkat produktifitas keuangan masyarakat menjadi lebih baik.

Pelaksanaan program ini bukan saja di laksanakan pada kota-kota besar, akan tetapi dilaksanakan juga pada tingkat terkecil dari sebuah wilayah, salah satu yang menjadi objek program pengembangan wirausaha ini yaitu Desa Tangga. Desa Tangga termasuk salah satu Desa yang terletak di Kecamatan Monta Kabupaten Bima Nusa Tenggara Barat. Desa tangga merupakan pusat Kecamatan Monta dimana bangunanbangunan umum kecamatan Monta berada di Desa Tangga seperti, Rumah Sakit, Bank, Kantor Camat, KUA, dll. Desa Tangga Kecamatan Monta memiliki jumlah penduduk dengan KK 980 orang yang terdir terdiri dari laki-laki: 1897 jiwa, perempuan 1997 jiwa, sebagian besar dari jumlah masyarakat berprofesi sebagai petani, peternak, PNS dan buruh tani, sebagianya lagi tidak bekerja. Untuk bagian peternakan, masyarakat Desa Tangga memilih beberapa hewan untuk dipelihara, yaitu: sapi, bebek, kambing, dan ayam potong. Sedangkan pada sector pertanian, masyarakat lebih memilih untuk menanam jagung, padi, pisang dan bawang. Desa Tangga merupakan salah satu Desa penghasil pisang terbesar di Kecamatan monta. Menanggapi situasi yang terjadi tersebut, Mahasiswa Universitas Mataram, memberikan sebuah terobosan berupa usaha kuliner dengan program pengembangan produk yang berbahan dasar pisang menjadi berbagai menu cemilan, dan lebih memfokuskan dalam memproduksi (Sate Pisang Varian Rasa). Kegiatan dalam penerapan program pengembangan produk usaha yang berbahan Dasar pisang di Desa Tangga Kecamatan Monta, terdiri dari: analisis kebutuhan masyarakat dan Pekebun, persiapan, pelaksanaan dan promosi produk. Hasil dari Program tersebut di tunjukkan untuk meningkatkan kualitas Ekonomi masyarakat terutama pekebun pisang di Desa Tangga, proses kegiatan program ini diharapkan mampu diaplikasikan dengan baik dan dapat menjadi jembatan bagi masyarakat desa Tangga menuju perekonomian yang lebih baik.

\section{Metode}

Kegiatan ini menggunakan teknik Focus Group Discussion (FGD) yang melibatkan kelompok-kelompok masyarakat, kelompok remaja dan ibu rumah tangga yang ada di Desa Tangga, dimana sosialisasi tentang bagaimana pengolahan pisang menjadi sate pisang dan berbagai aneka cemilan yang enak, sehat, dan berdaya jual tinggi. Pelatihan dan bimbingan teknis pembuatan sate pisang menggunakan Bantuan teknologi berupa : kamera dan hand phone (HP), dan beberapa peralatan untuk pelatihan yang dibutuhkan untuk kegiatan ini.

Adapun langkah-langkah kegiatan yang di lakukan selama KKN yaitu: Mengantar surat pengantar KKN kepada pihak Desa, dan pada minggu pertama mahasiswa KKN menyusun Proposal sebagai awalan KKN. Pada minggu kedua, mahasiswa melakukan sosialisasi terkait kegiatan yang akan di laksanakan bersama warga di desa serta melakukan survey ke beberapa kebun pisang untuk memastikan ketersediaan pisang untuk diolah. Pada minggu ketiga, mahasiswa melakukan pelatihan pembuatan produk bersama warga di desa. Pada minggu ke empat mahasiswa melakukan sosialisasi terkait cara pemasaran produk yang efektif. Dan pada setiap hari jum'at tim pengabdian masyarakat melakukan bakti sosial di desa seperti membantu membersihkan kantor desa, membersihkan masjid, dan tempat-tempat yang di butuhkan lainnya.

\section{Hasil dan Pembahasan}

\section{Analisis kebutuhan}

Desa Tangga merupakan salah satu Desa penghasil pisang terbesar di Kecamatan monta. Melihat hal tersebut masayarakat memiliki peluang yang sangat besar dalam pengembangan wirausaha berupa kuliner yang berbahan dasar pisang. Untuk sekarang ini, olahan pisang menjadi salah satu makanan yang diminati banyak kalangan, karena rasanya yang enak dan manfaatnya yang banyak. Sehingga warga Desa Tangga di harapkan dapat memenuhi permintaan konsumen dengan menyediakan sektor lingkungan yang menjanjikan. Namun disisi lain, sangat di sayangkan, masyarakat belum terlalu paham bagaimana cara pengolahan pisang menjadi berbagai macam cemilan enak dan sehat. 


\section{Tahap Persiapan}

Pada tahap persiapan dilakukan sosialisasi kegiatan program pengembangan produk yang berbahan dasar pisang (Sate Pisang Varian Rasa) yang dilaksanakan di desa Tangga kecamatan Monta. Sosialisasi dilaksanakan bersama remaja dan ibu-ibu di Desa Tangga. Sosialisasi ini bertujuan untuk memotivasi masyarakat di Desa Tangga untuk menciptakan wirausaha baru dengan produk-produk yang unik yang akan di bantu oleh mahasiswa KKN, dan warga pun memberikan apresiasi atas hal tersebut dengan menyediakan tempat untuk melakukan sosialisasi tersebut.

\section{Kegitan Pelaksaan Program}

Pada tahap ini kegitan pelaksaan program pembuatan produk Sate Pisang Varian Rasa telah mengiikut sertakan masyarakat di Desa Tangga. masyarakat yang tergabung dalam pelaksanaan pembuatan Sate Pisang yaitu ibu-ibu dan anak-anak muda (remaja) yang memiliki antusias dalam belajar memasak.

\section{Faktor-Faktor Pendukung Terlaksananya Kegiatan}

Respon dari masyarakat terhadap kegiatan pemberdayaan masyarakat yang diberikan oleh Tim pengabdian masyarakat Universitas Mataram mendapat antusiasme yang tinggi dari masyarakat dalam mengikuti kegiatan tersebut, sehingga kegiatan ini perlu dilakukan secara berkelanjutan untuk membantu masyarakat dalam meningkatkan pendapatan keluarga dengan memanfaatkan buah pisang untuk di jadikan menu cemilan yang unik, sehat dan enak.

\section{Faktor-Faktor penghambat kegiatan dan cara mengatasinya}

Kegiatan pengabdian kepada masyarakat ini secara umum dapat dilakukan sesuai dengan rencana. Akan tetapi pelaksanaan kegiatan sering tertunda dikarenakan menyesuaikan jadwal masingmasing warga, sehingga cara untuk mengatasi masalah tersebut adalah dengan melakukan sosialisasi bergilir mengikuti waktu luang warga terkait kegiatan yang akan di laksanakan. Namun pada akhirnya pelaksanaan kegiatan ini secara umum dapat dilakukan sesuai dengan prosedur kerja yang telah ditetapkan.

Pengolahan produk Sate Pisang pada dasarnya sangatlah mudah (Jika hanya diproduksi dalam bentuk yang biasa saja) namun mahasiswa KKN Universitas Mataram mencoba memberikan terobosan baru berupa Sate Pisang dengan Varian Rasa yang enak. Hal tersebut dilakukan agar produk memiliki nilai jual dan berdaya saing tinggi.

Pada dasarnya masyarakat desa Tangga memiliki beberapa olahan makanan yang berbahan dasar pisang, akan tetapi makan yang diproduksi tidak terlalu memiliki nilai jual yang tinggi karena mereka mengolah hanya dengan menggoreng dan merebus saja, sehingga diperkirakan sangat membosankan para konsumen untuk mengonsumsi olahan tersebut, sehingga dalam peningkatan perekonomian sangatlah kurang. Oleh karena itu dalam kegiatan ini, kami melaksanakan sosialisasi untuk memberikan edukasi kepada masyarakat terkait dengan pembuatan produk-produk yang berbahan dasar pisang dan cara pemasaran yang baik dan benar agar laku di pasaran sehingga dapat memperbaiki dan meingkatkan perekonomian masyarakat setempat.

\section{Berikut beberapa gambaran rangkaian kegiatan yang dilaksanakan bersama masyarakat:}
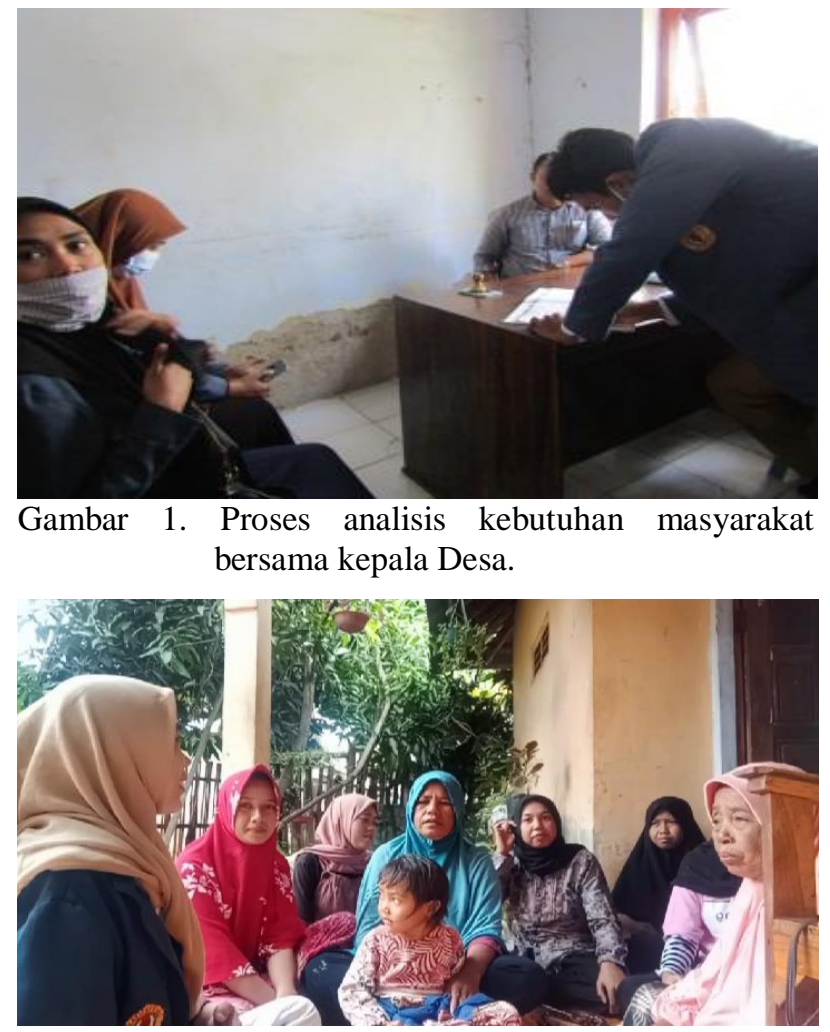

Gambar 2. Tahap sosialisasi mengenai program yang akan dilaksanakan, yaitu pembuatan Sate Pisang Varian Rasa. 

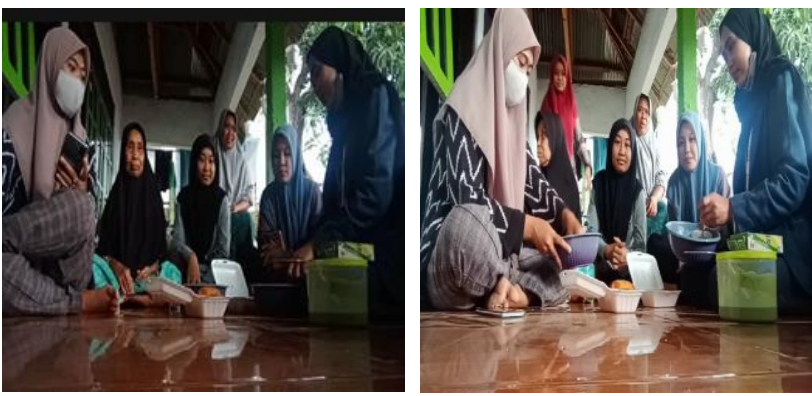

Gambar 3. Proses pembuatan Sate Pisang Varian Rasa bersama remaja dan Ibu-ibu Desa Tangga.

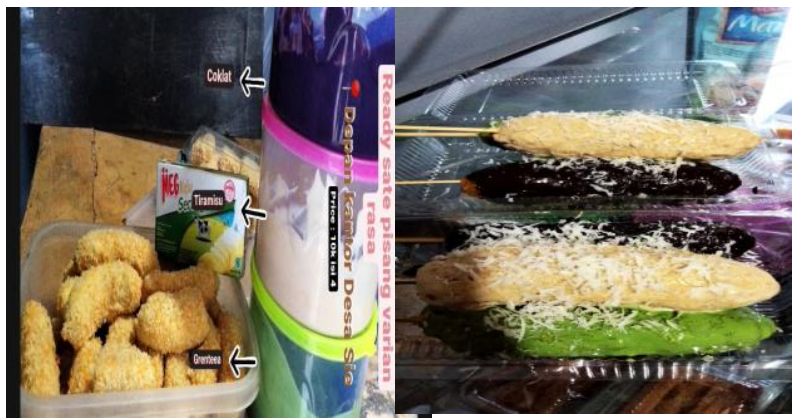

Gambar 4. Hasil dari pembuatan Sate Pisang

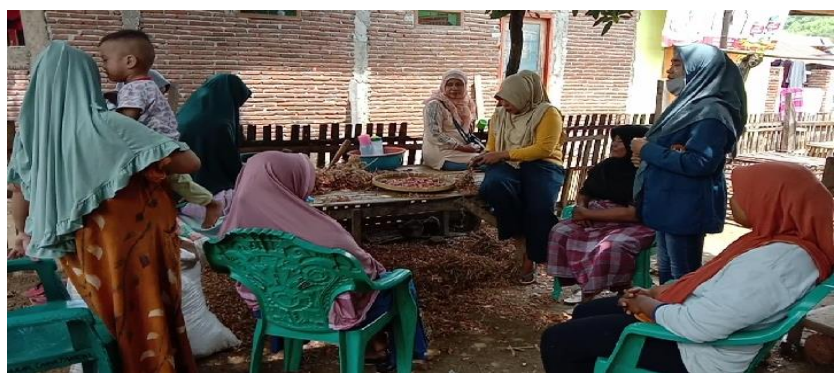

Gambar 5. Tahap pembekalan cara promosi produk yang telah di hasilkan.

\section{Kesimpulan}

Penerapan program pengembangan produk usaha yang berbahan Dasar Pisang (Sate Pisang) pada masyarakat Desa Tangga Kecamatan Monta, terdiri dari analisis kebutuhan masyarakat dan Pekebun, persiapan, pelaksanaan dan promosi produk. Hasil dari Program tersebut bertujuan untuk meningkatkan kuantitas perekonomian masyarakat terutama Pekebun di Desa Tangga. Proses kegiatan program pada masyarakat, diharapkan mampu di aplikasikan dengan sebaikbaiknya sehingga tercipta sebuah jembatan bagi masyarakat menuju perekonomian yang lebih baik dari sebelumnya.

\section{Daftar Pustaka}

Alexius Endy Budianto, Eris dianawati, Didik iswahyudin (2019) Penerapan Program Pengembangan Kewirausahaan Pada Mahasiswa (Tenant) di Universitas Kanjuruhan malang: kurmawula : Jurnal Pengabdian Kepada Masyarakat.

Budijanto, S. 2016. Dukungan iptek bahan pangan pada pengembangan tepung lokal. Jurnal Pangan, 18(2), 55-67.

Dedi Rohaendi. 2009. Memproduksi Kerupuk Sangria.Gramedia Pustaka Utama.

Farida Nur Kumala, Muhammad Nur Hudha, Sudi Dul Aj. (2019) Pelatihan Pemasaran Produk Olahan Telo Ungu Di Desa Wonosari Kecamatan Wonosari Gunung Kawi Kabupaten Malang:Jurnal Pengabdian Kepada Masyarakat.

Jupri, A., Ahydi. H., Rozi, T \& Nurhasanah. (2020) Pengenalan Ddiverifikasi Pengolahan Air Nira Menjadi Gurla Aren dan Gula Semut Serta Berbagai Aneka Rasa Minuman Di Desa Langko Kecamatan Lingsar Lombok Barat: Jurnal pendidikan Magister pendidikan IPA 3(2)

Matematika \& Sains. Hal. 50 - 60.

Panduan Penelitian dan Pengabdian Masyarakat Edisi X 2016, DP2M Dikti Jakarta.

Qomariah, N. 2016. Pemberdayaan Masyarakat Desa Melalui Pengembangan "Soft Skill Pembuatan Krupuk Samiler dalam Upaya Peningkatan Pendapatan Keluarga di Kabupaten Bondowoso. Jurnal Pengabdian Masyarakat Ipteks, 1 (2).

Ria arifianti, Mohammad Benny alexsandri, Lina Auliana,. (2018) Pemetaan Aktivitas Bisnis Kreatif Di Kecamatan Andir: Jurnal Pengabdian Kepada Masyarakat.

Rusdi, B., IT. Maulana, dan R.A. Kodir. 2013. Analisa Kualitas Tepung Ampas Tahu. Jurnal

Substitusi Tepung Ampas Tahu Terhadap Kualitas Cookies. E-Journal Home Economic and Tourism, 4 (3). 
Suhartini, S. Dan N, Hidayat 2005. Aneka OlahanAmpas Tahu. Cetakan I. Surabaya. Trubus Agrisarana. Suharto, 2011. Teknologi Pengawetan Pangan.

Sunartiningsih, Agnes. 2004. Pemberdayaan Masyarakat Desa Melalui Institusi Lokal. Aditya Media;Yogyakarta.

Suparjan dan Hempri Suyatno. 2003. Pengembangan Masyarakat, Pembangunan sampai Pemberdayaan. Aditya Media : Yogyakarta 